\title{
RETRACTED ARTICLE: Multimedia Effect in Problem Solving: a Meta-analysis
}

\author{
Liru Hu${ }^{1} \cdot$ Gaowei Chen ${ }^{1} \cdot$ Pengfei $\mathrm{Li}^{2} \cdot$ Jing Huang ${ }^{3}$ \\ Published online: 11 July 2019 \\ (C) Springer Science+Business Media, LLC, part of Springer Nature 2019
}

The authors have retracted this article [1] in its initial published form after receiving comments from an anonymous reviewer. They agree that some parts, especially in the data coding and the interpretation thereof, could cause confusion to the reader. These issues do not affect the major findings, however, the authors also find that the article can and should be improved. The authors are grateful to have been given the opportunity to resubmit the article with corrections. All authors have agreed to this retraction.

The online version of this article contains the full text of the retracted article as electronic supplementary material.

[1] Hu, L., Chen, G., Li, P. et al. Multimedia Effect in Problem Solving: a Meta-analysis. Educ Psychol Rev (2019). https://doi.org/10.1007/s10648-019-09490-4

Electronic supplementary material The online version of this article (https://doi.org/10.1007/s10648-01909490-4) contains supplementary material, which is available to authorized users.

Liru $\mathrm{Hu}$

liruhu.hku@gmail.com

1 Faculty of Education, The University of Hong Kong, Hong Kong 999077, China

2 School of Education, Shaanxi Normal University, Xi'an 710062, China

3 Office of the Vice President (Academic), The Education University of Hong Kong, Hong

Kong 999077, China 